\title{
Study of common variants of the apolipoprotein $E$ and lipoprotein lipase genes in patients with coronary heart disease and variable body mass index
}

\author{
Genovefa D. Kolovou, ${ }^{1}$ Vana Kolovou, ${ }^{1,2}$ Demosthenes B. Panagiotakos, ${ }^{3}$ \\ loannis Vasiliadis, ${ }^{1,4}$ Vassiliki Giannakopoulou, ${ }^{5}$ Peggy M. Kostakou, ${ }^{5}$ \\ Vassiliki Vartela, ${ }^{1}$ Sophie Mavrogeni ${ }^{1}$ \\ ${ }^{1}$ Cardiology Department, ${ }^{2}$ Molecular Immunology Laboratory, Onassis Cardiac Surgery Center, Athens, Greece, ${ }^{3}$ Harokopio \\ University, Athens, Greece, ${ }^{4}$ Royal Free Hospital-University College of London (UCL), London, UK, ${ }^{5}$ Cardiology Department, \\ Thriassio General Hospital, Athens, Greece
}

\begin{abstract}
OBJECTIVE: In the present study, we evaluated the influence of lipoprotein lipase (LPL) and apolipoprotein (apo) E polymorphisms on lipid concentrations of 178 Greek men of similar age with coronary heart disease (CHD), but varying body mass index (BMI). DESIGN: Patients were divided according to their $B M I\left(\right.$ in $\left.\mathrm{kg} / \mathrm{m}^{2}\right)$ into three groups: lean $(B M I=20-24.9)$, overweight $(B M I=25-29.9)$, and obese (BMI $\geq 30$ ). Polymorphisms of LPL (HindIII, S447X) and apo E ( $\varepsilon 2$, $\varepsilon 3, \varepsilon 4)$, and lipid parameters were studied. RESULTS: There was a negative correlation between BMI and high-density lipoprotein cholesterol (HDL-C) concentration $(r=-0.272, p<0.001)$, as has already been described. Lean homozygotes for the HindIII(+) allele had higher HDL-C levels compared to lean homozygotes for the HindIII(-) allele $(\mathrm{p}=\mathbf{0 . 0 1 2})$. No correlation was found between S447X or apo E polymorphisms and BMI or plasma lipids in any group. Overweight men with the $\varepsilon 3 / \varepsilon 3$ and SS genotypes had higher triglycerides concentration compared with overweight men with $\varepsilon 3 / \varepsilon 3$ and $\mathrm{SX}(\mathrm{p}=0.002)$. CONCLUSIONS: The HindIII polymorphism alone may influence HDL-C concentration in lean men, in contrast to $S 447 \mathrm{X}$ alone, which has no influence on any lipid parameters. However, the $\mathrm{S} 447 \mathrm{X}$ and apo $\mathrm{E}$ polymorphisms may have a synergetic effect and alter plasma triglyceride concentration in overweight men.
\end{abstract}

Key words: Apolipoprotein E, Body mass index, Coronary heart disease, Lipids, Lipoprotein lipase, Polymorphism

Address for correspondence:

Genovefa D. Kolovou, MD, PhD, FESC, SFASA

Onassis Cardiac Surgery Center

356 Sygrou Ave., 17674 Athens, Greece

Tel: +30 2109493520 , Fax: +30 2109493336

E-mail: genovefa@kolovou.com

Received: 11-05-2014, Accepted: 13-01-2015

\section{INTRODUCTION}

Coronary heart disease (CHD) is a multifactorial disease caused by a combination of genetic and environmental factors. Among them, abnormal plasma lipid concentrations are the major risk factors for CHD. On the other hand, obesity, being a chronic 
disease, leads to metabolic abnormalities and increased mortality because of the accumulation of body fat. ${ }^{1}$ In obese subjects, the main lipid disorder is increased triglyceride (TG) levels, due to increased free fatty acid released by adipose tissue, leading to increased very low-density lipoprotein cholesterol (VLDL) production by the liver. ${ }^{2,3}$ Genes whose expression products are involved in lipoprotein metabolism as lipoprotein lipase (LPL) ${ }^{4}$ and apolipoprotein (apo) $\mathrm{E}^{5,6}$ are considered excellent candidates for studying susceptibility to CHD. In particular, LPL plays a key role in lipoprotein metabolism by hydrolyzing TGs from VLDLs and chylomicrons and also by removing lipoproteins from the circulation..$^{7-9}$ Furthermore, LPL is implicated in atherogenesis since it influences both the interaction between atherogenic lipoproteins and cell surface and the receptors on the vascular wall. ${ }^{10-12}$ Several studies have described more than 60 different mutations of the LPL gene leading to a reduction in enzyme synthesis and activity. One of the most frequent polymorphisms of LPL, the S447X polymorphism with an incidence of $17-22 \%$ in Caucasian populations, ${ }^{13,14}$ seems to be favorable for the catabolism of VLDLs, decreasing fasting concentrations of TGs. ${ }^{15-17}$ In particular, the $S$ allele has been associated with higher TG levels, ${ }^{18}$ while the $\mathrm{X}$ allele has been linked to anti-atherogenic lipid profiles and a modest reduction in coronary disease risk. ${ }^{19}$ On the other hand, the S447X polymorphism was not correlated with the incidence of CHD. ${ }^{20}$ Another common LPL gene polymorphism is the HindIII polymorphism. As regards HindIII alleles, the common allele $(+)$ is significantly associated with high TG levels and low high-density lipoprotein cholesterol (HDL-C) levels compared with the rare allele (-). ${ }^{21-23}$ Furthermore, the LPL $(+/+)$ genotype has demonstrated a higher risk of myocardial infraction. ${ }^{24}$ Apo E, as a component of TG-rich lipoproteins which was first discovered in 1970, ${ }^{25}$ is an amphipathic glycoprotein mediating the distribution of lipids and cholesterol among cells, expressed mainly by the brain and liver. ${ }^{26}$ Apo $\mathrm{E}$ is polymorphic and presents three common alleles: $\varepsilon 2$, $\varepsilon 3$, and $\varepsilon 4$. It seems that $\varepsilon 2$ carriers are characterized by lower low-density lipoprotein and apo B levels but higher HDL-C and apo A-I levels than $\varepsilon 3$ carriers, while the opposite has been found for $\varepsilon 4$ carriers compared with $\varepsilon 3$ carriers. ${ }^{27-31}$ Therefore, we evaluated the polymorphisms of LPL (HindIII, S447X) and apo
$\mathrm{E}(\mathrm{e} 2, \mathrm{e} 3, \mathrm{e} 4)$ and their influence on lipid values in Greek men with CHD grouped by their body mass index (BMI). Additionally, we studied the synergetic effect of LPL and apo E on lipid values.

\section{SUBJECTS AND METHOLOGY}

\section{Subjects}

One hundred and seventy-eight (178) unrelated Greek men with angiographically documented CHD were divided into three groups: lean (BMI=20-24.9 kg/ $\left.\mathrm{m}^{2}\right)$, overweight $\left(\mathrm{BMI}=25-29.9 \mathrm{~kg} / \mathrm{m}^{2}\right)$, and obese (BMI $\left.\geq 30.0 \mathrm{~kg} / \mathrm{m}^{2}\right)$. All subjects were included irrespectively of concomitant risk factors, namely smoking, arterial hypertension, dyslipidemia, and diabetes mellitus. The lipid values of patients who were on hypolipidemic treatment were taken from the patient's file in the pre-treatment period (not during the first days after acute myocardial infarction). The Ethics Committee of the Onassis Cardiac Surgery Center approved the protocol of this study. All patients included in the study provided written informed consent.

\section{Genotyping}

After the recruitment of the study population, LPL and apo E genotyping was performed. The analysis of the HindIII (+/+, +/-, -/-) and S447X (SS, SX, XX) genotypes was prepared as described by Humphries et al. ${ }^{32}$ The analysis of apo E genotypes $(\varepsilon 2 / \varepsilon 2, \varepsilon 2 /$ $\varepsilon 3, \varepsilon 2 / \varepsilon 4, \varepsilon 3 / \varepsilon 3, \varepsilon 3 / \varepsilon 4, \varepsilon 4 / \varepsilon 4)$ was performed as described by Hixson and Vernier. ${ }^{33}$ The analyses of the biochemical parameters were performed as described in a previous study. ${ }^{34}$

\section{Statistical Analysis}

Categorical variables are presented as relative frequencies. Numerical variables were tested for normality of their distribution and are presented as mean values plus or minus one standard deviation, unless otherwise stated. The statistical evaluation was based on the calculation of the chi-square criterion using Yates' correction for continuity. Comparisons of patients' quantitative characteristics among BMI groups were performed by ANOVA or the KruskalWallis test, whichever appropriate, while comparison between two groups was performed with the use of the independent samples t-test or Mann-Whitney U test, whichever appropriate. Spearman's correlation 
coefficient was calculated for the correlation between BMI and HDL-C. All reported P-values are from twosided tests. P-values less than 0.05 were considered to be statistically significant.

STATA 6 software was used for the calculations (STATA Corp. College Station, Texas, USA).

\section{RESULTS}

All clinical characteristics and lipid values are presented in Table 1.

\section{BMI and lipid values}

There was a negative correlation between BMI and HDL-C concentration (Spearman's correlation coefficient $\mathrm{r}=-0.272, \mathrm{p}<0.001$ ).

\section{Genotype and allele distribution}

There was no difference in genotype or allele distribution among groups (Table 2 and Table 3 ).
Table 2. The distribution (in \%) of LPL and apo E genotypes by BMI

\begin{tabular}{ccccc}
\hline & $\begin{array}{c}\text { Lean } \\
\mathbf{n}=\mathbf{5 0}\end{array}$ & $\begin{array}{c}\text { Overweight } \\
\mathbf{n = 9 4}\end{array}$ & $\begin{array}{c}\text { Obese } \\
\mathbf{n = 3 4}\end{array}$ & $\begin{array}{c}\text { Overall } \\
\mathbf{n}=\mathbf{1 7 8}\end{array}$ \\
\hline LPL & & & & \\
S447X & & & & \\
SS & 72.0 & 79.8 & 79.4 & 77.5 \\
SX & 26.0 & 19.1 & 20.6 & 21.3 \\
XX & 2.0 & 1.1 & 0.0 & 1.1 \\
HindIII & & & & \\
$+/+$ & 34.0 & 47.9 & 47.1 & 43.8 \\
$+/-$ & 52.0 & 42.6 & 44.1 & 45.5 \\
$-/-$ & 14.0 & 9.6 & 8.8 & 10.7 \\
Apo E & & & & \\
$\varepsilon 2 / \varepsilon 3$ & 6.0 & 7.4 & 8.8 & 7.3 \\
$\varepsilon 2 / \varepsilon 4$ & 2.0 & 1.1 & 2.9 & 1.7 \\
$\varepsilon 3 / \varepsilon 3$ & 82.0 & 76.6 & 61.8 & 75.3 \\
$\varepsilon 3 / \varepsilon 4$ & 8.0 & 13.8 & 23.5 & 14.0 \\
$\varepsilon 4 / \varepsilon 4$ & 2.0 & 1.1 & 2.9 & 1.7 \\
\hline
\end{tabular}

Table 1. Clinical characteristics of all groups. Comparisons of patients' quantitative characteristics among BMI groups were performed by ANOVA or the Kruskal-Wallis test, as appropriate

\begin{tabular}{lcccc}
\hline & Lean $\mathbf{n}=\mathbf{5 0}$ & Overweight $\mathbf{n}=\mathbf{9 4}$ & Obese $\mathbf{n}=\mathbf{3 4}$ & P \\
\hline Age (years) & $64 \pm 10$ & $61 \pm 10$ & $63 \pm 9$ & 0.130 \\
BMI & $23 \pm 1$ & $27 \pm 1$ & $32 \pm 2$ & $<0.001$ \\
Smoking (current, n\%) & 28 & 26 & 47 & 0.059 \\
TC (mg/dl) & $236 \pm 48$ & $233 \pm 58$ & $225 \pm 49$ & 0.670 \\
TG (mg/dl) & $152 \pm 94$ & $175 \pm 121$ & $179 \pm 74$ & 0.451 \\
HDL-C (mg/dl) & $44 \pm 11$ & $37 \pm 9$ & $36 \pm 10$ & $<0.001$ \\
LDL-C (mg/dl) & $163 \pm 45$ & $158 \pm 48$ & $152 \pm 45$ & 0.613 \\
Apo A (mg/dl) & $119 \pm 24$ & $116 \pm 25$ & $110 \pm 25$ & 0.299 \\
Apo B (mg/dl) & $93 \pm 30$ & $98 \pm 26$ & $99 \pm 38$ & 0.633 \\
Glucose (mg/dl) & $129 \pm 63$ & $133 \pm 60$ & $135 \pm 68$ & 0.909 \\
SBP (mm Hg) & $148 \pm 22$ & $151 \pm 26$ & $154 \pm 23$ & 0.555 \\
DBP (mm Hg) & $80 \pm 11$ & $82 \pm 11$ & $83 \pm 12$ & 0.553 \\
No. of arteries & $2.4 \pm 0.7$ & $2.1 \pm 0.9$ & $2.3 \pm 0.7$ & 0.180 \\
Previous MI (n \%) & 66 & 61 & 53 & 0.427 \\
Diabetes mellitus (n \%) & 24 & 31 & 38 & 0.374 \\
Hypertension (n \%) & 70 & 72 & 79 & 0.619 \\
\hline
\end{tabular}

Apo: apolipoprotein; HDL-C: high-density lipoprotein cholesterol; LDL-C: low-density lipoprotein cholesterol; DBP: diastolic blood pressure; No of arteries: number of stenosed coronary arteries more than $50 \%$ of lumen diameter; MI: myocardial infarction; SBP: systolic blood pressure; TC: total cholesterol; TG: triglycerides.

Continuous variables are presented as mean $( \pm)$ one standard deviation, while qualitative variables are presented as relative frequencies. 
Table 3. The distribution (in \%) of LPL and apo E alleles by BMI

\begin{tabular}{lcccc}
\hline & $\begin{array}{c}\text { Lean } \\
\mathbf{n = 5 0}\end{array}$ & $\begin{array}{c}\text { Overweight } \\
\mathbf{n = 9 4}\end{array}$ & $\begin{array}{c}\text { Obese } \\
\mathbf{n = 3 4}\end{array}$ & $\begin{array}{c}\text { Overall } \\
\mathbf{n = 1 7 8}\end{array}$ \\
\hline LPL & & & & \\
S447X & & & & \\
$\quad$ S & 85.0 & 89.4 & 89.7 & 88.2 \\
$\quad$ X & 15.0 & 10.6 & 10.3 & 11.8 \\
HindIII & & & & \\
+ & 60.0 & 69.1 & 69.1 & 66.6 \\
- & 40.0 & 30.9 & 30.9 & 33.4 \\
Apo E & & & & \\
$\varepsilon 2$ & 4.0 & 4.3 & 5.9 & 4.5 \\
$\varepsilon 3$ & 89.0 & 87.2 & 77.9 & 86.0 \\
$\varepsilon 4$ & 7.0 & 8.5 & 16.2 & 9.6 \\
\hline
\end{tabular}

\section{Correlations}

Lean homozygotes for the HindIII $(+)$ allele $(n=17)$ had higher HDL-C concentration compared with lean homozygotes for the HindIII(-) allele (n=7) [in mg/ $\mathrm{dl} ; 46(95 \%$ CI for mean $40-51)$ vs 34 (95\% CI for mean 29-39), $\mathrm{p}=0.012]$. No difference was found between the apo E or S447X polymorphisms and plasma lipids in any group.

No any association between the LPL polymorphism and number of stenosed arteries was found.

\section{LPL plus apo E genotype distribution}

Overweight patients with the apo $\varepsilon 3 / \varepsilon 3$ and SS genotypes $(n=61)$ had higher plasma TG concentration compared with overweight patients with the apo $\varepsilon 3 / \varepsilon 3$ and $\mathrm{SX}$ genotypes $(\mathrm{n}=10)[\mathrm{in} \mathrm{mg} / \mathrm{dl} ; 189(95 \%$ CI for mean 150-228) vs 121 (95\% CI for mean 101$149), \mathrm{p}<0.002)$.

\section{DISCUSSION}

These data demonstrate that the polymorphism of HindIII alters plasma HDL-C in lean subjects, in contrast to the S447X or apo E polymorphisms, which do not appear to have any effect on plasma lipids in any group. The presence of a specific combination of S447X and apo E polymorphisms alters plasma TG concentration in overweight men.

In the Bogalusa Heart Study, ${ }^{35}$ the TG levels, adjusted for age and BMI were lower in carriers versus non-carriers of the $\mathrm{X}$ allele. We have found that TG levels were higher in the SS genotype versus the SX in homozygosity for the apo $\varepsilon 3$ allele, and only in overweight subjects. Barg reported that carriers of the $\mathrm{X}$ allele have lower TG and higher HDL-C levels as well as a reduced risk of CHD. ${ }^{36}$ Agirbasli $\mathrm{M}$ et al reported that the S447X variant of the LPL gene is inversely associated with severity of CHD and lower TG and HDL-C levels. ${ }^{37}$ Also in a recent study, the LPL gene polymorphism was shown to be associated with the consumption of alcohol and unsaturated fat and to modulate serum HDL-C levels. Specifically, the $\mathrm{X}$ allele was positively associated with HDL-C concentrations $(\mathrm{p}<0.001) .{ }^{38}$ Furthermore, the S447X polymorphism of the LPL gene may play a role in the risk of atherogenic sdLDL fraction. ${ }^{39}$ The study of Shimo-Nakanishi et $\mathrm{al}^{4}$ demonstrated that the HindIII polymorphism was associated with increased risk of atherothrombotic infarction; however, they did not find the HindIII allele to be significantly correlated with plasma levels of total cholesterol, TG, or HDL-C. By contrast, in the present study we found that in lean patients, homozygotes for the HindIII(+) allele had higher HDL-C than homozygotes for the HindIII(-) allele. Abd-El-Aziz et al presented a synergistic interaction between the $\mathrm{H} 2 \mathrm{H} 2$ genotype of the LPL gene and the S2S2 genotype of the apo C3 gene which leads to increased severity of CHD. ${ }^{40} \mathrm{Al}$-Jafari et al reported than the odds ratio of the HindIII genotype $\mathrm{H}(+/+)$ vs the $\mathrm{H}(-/-)$ genotype at $95 \%$ Confidence Interval were $4.6(1.57-13.2)$ and $\mathrm{p}<0.005$, hence showing no significant association with $\mathrm{CHD} .{ }^{41}$ Munshi et al reported that TGs were found to be elevated in individuals bearing the HindIII $(+/+)$ genotype in comparison with the HindIII (-/-) genotype, but only in the presence of significantly lower HDL-C levels. ${ }^{42}$ Additionally, Muñoz-Barrios reported that the genotype $\mathrm{T} / \mathrm{T}$ of HindIII was associated with increase of total cholesterol $(\beta=23.6 \mathrm{mg} / \mathrm{mL}$; $\mathrm{p}=0.03){ }^{43}$ while Rebhi et al referred to a significant association between the genotype of the HindIII polymorphism and lower HDL-C and TG levels. ${ }^{44}$

Reports on the association between lipid variables and the HindIII polymorphism have been controversial. ${ }^{45}$ Several studies have reported a significant association between the HindIII(+) allele and higher TG or lower HDL-C levels, ${ }^{46-48}$ findings not in line with 
those of Heinzmann et al. ${ }^{49}$ There are also controversial results regarding the LPL polymorphism and obesity. Vohl et al ${ }^{50}$ suggested that the HindIII polymorphism might modulate the magnitude of the dyslipidemic state associated with visceral obesity. They found that visceral obesity was associated with increased TG concentrations in HindIII(+/+) homozygous men, suggesting that visceral obesity may lead to hypertriglyceridemia in the presence of the HindIII $(+/+)$ genotype. In the HindIII(+/-) group, variation in the amount of visceral obesity was not associated with differences in TG concentration. Similar results were found by Jemaa et al. ${ }^{51}$ They also reported that the plasma TG levels varied significantly among the HindIII genotypes $[(+/+)$ had the highest TG levels] and that the HindIII polymorphism showed a significant association with HDL2-C. These associations were only observed in females and could not be explained by the variations in BMI and age.

In the present study we also found an association between the LPL polymorphism and serum HDL-C in lean subjects with CHD. This was the only association found concerning LPL polymorphisms alone. However, overweight subjects with the $\varepsilon 3 / \varepsilon 3$ and SS genotypes had altered plasma TG concentration. These findings indicate that the apo E genotype and heterogeneity at the LPL gene locus may have an interactive effect on plasma lipid and lipoprotein levels in overweight subjects.

This type of study has several limitations. For example, certain apo E and LPL polymorphisms may cause premature death from CHD and therefore such patients may be under-represented in the study. Environmental factors such as lifestyle modifications may influence the expression of the apo E and LPL genotypes. Additionally, we did not find any significant differences in the obese group concerning lipid variables, probably due to the small number of patients carrying the less frequent genotypes, as is true of most populations. Furthermore, local factors (e.g. the Mediterranean diet) may also exert some influence.

In conclusion, our results suggest that the HindIII polymorphism alone may influence the HDL-C concentration in healthy-weight men with CHD, in contrast to S447X alone, which has no influence on any lipid parameters. However, the presence of both
S447X and apo E polymorphisms probably has a synergetic effect and alters plasma TG concentration in overweight men. No other differences were found between LPL or apo E polymorphisms and BMI or plasma lipids in any group. Nevertheless, further prospective investigations in large populations among various races are required to confirm these findings.

\section{REFERENCES}

1. Parekh S, Anania FA, 2007 Abnormal lipid and glucose metabolism in obesity: implications for nonalcoholic fatty liver disease. Gastroenterology 132: 2191-2207.

2. Qureshi K, Abrams GA, 2007 Metabolic liver disease of obesity and role of adipose tissue in the pathogenesis of nonalcoholic fatty liver disease. World J Gastroenterol: 13: 3540-3553.

3. Chan DC, Barrett HP, Watts GF, 2004 Dyslipidemia in visceral obesity: mechanisms, implications, and therapy. Am J Cardiovasc Drugs 4: 227-246.

4. Shimo-Nakanishi Y, Urabe T, Hattori N, et al, 2001 Polymorphism of the lipoprotein lipase gene and risk of atherothrombotic cerebral infarction in the Japanese. Stroke 32: 1481-1486.

5. Song Y, Stampfer MJ, Liu S, 2004 Meta-analysis: apolipoprotein E genotypes and risk for coronary heart disease. Ann Intern Med 141: 137-147.

6. Kolovou G, Daskalova D, Mikhailidis DP, 2003 Apolipoprotein E polymorphism and atherosclerosis. Angiology 54: 59-71.

7. Pykälistö OJ, Smith PH, Brunzell JD, 1975 Determinants of human adipose tissue lipoprotein lipase: effect of diabetes and obesity on basal- and diet-induced activity. J Clin Invest 56: 1108-1117.

8. Taylor KG, Holdsworth G, Galton DJ, 1977 Clofibrate increases lipoprotein-lipase activity in adipose tissue of hypertriglyceridaemic patients. Lancet 8048: 1106-1107.

9. Eckel RH, 1989 Lipoprotein lipase: a multifunctional enzyme relevant to common metabolic diseases. N Engl J Med 320: 1060-1067.

10. Beisiegel U, Weber W, Bengtsson-Olivecrona G, 1991 Lipoprotein lipase enhances the binding of chylomicrons to low density lipoprotein receptor-related protein. Proc Natl Acad Sci USA 88: 8342-8346.

11. Mulder M, Lombardi P, Jansen H, van Berkel TJ, Frants RR, Havekes LM, 1993 Low density lipoprotein receptor internalizes low density and very low density lipoproteins that are bound to heparan sulfate proteoglycans via lipoprotein lipase. J Biol Chem 268: 9369-9375.

12. Salinelli S, Lo JY, Mims MP, Zsigmond E, Smith LC, Chan L, 1996 Structure-function relationship of lipoprotein lipase-mediated enhancement of very low density lipoprotein binding and catabolism by the low density lipoprotein receptor: functional importance of 
a properly folded surface loop covering the catalytic center. J Biol Chem 271: 21906-21913.

13. Jemaa R, Fumeron F, Poirier O, et al, 1995 Lipoprotein lipase gene polymorphisms: associations with myocardial infarction and lipoprotein levels, the ECTIM study. Etude Cas Témoin sur l'Infarctus du Myocarde. J Lipid Res 36: 2141-2146.

14. Groenemeijer BE, Hallman MD, Reymer PW, et al, 1997 Genetic variant showing a positive interaction with beta-blocking agents with a beneficial influence on lipoprotein lipase activity, HDL cholesterol, and triglyceride levels in coronary artery disease patients. The Ser447-stop substitution in the lipoprotein lipase gene. REGRESS Study Group. Circulation 95: 2628-2635.

15. Anagnostopoulou KK, Kolovou GD, Kostakou PM, et al, 2009 Sex-associated effect of CETP and LPL polymorphisms on postprandial lipids in familial hypercholesterolaemia. Lipids Health Dis 26: 24.

16. Henderson HE, Kastelein JJ, Zwinderman AH, et al, 1999 Lipoprotein lipase activity is decreased in a large cohort of patients with coronary artery disease and is associated with changes in lipids and lipoproteins. J Lipid Res 40: 735-743.

17. Kuivenhoven JA, Groenemeyer BE, Boer JM, et al, 1997 Ser447stop mutation in lipoprotein lipase is associated with elevated HDL cholesterol levels in normolipidemic males. Arterioscler Thromb Vasc Biol 17: 595-599.

18. Gigek Cde O, Chen ES, Cendoroglo MS, et al, 2007 Association of lipase lipoprotein polymorphisms with myocardial infarction and lipid levels. Clin Chem Lab Med 45: 599-604.

19. Wung SF, Kulkarni MV, Pullinger CR, Malloy MJ, Kane JP, Aouizerat BE, 2006 The lipoprotein lipase gene in combined hyperlipidemia: evidence of a protective allele depletion. Lipids Health Dis 5: 19.

20. Almeida KA, Strunz CM, Maranhao RC, Mansur AP, 2007 The S447X polymorphism of lipoprotein lipase: effect on the incidence of premature coronary disease and on plasma lipids. Arq Bras Cardiol 88: 297-303.

21. Peacock RE, Hamsten A, Nilsson-Ehle P, 1992 Associations between lipoprotein lipase gene polymorphisms and plasma correlations of lipids, lipoproteins and lipase activities in young myocardial infarction survivors and age-matched healthy individuals from Sweden. Atherosclerosis 97: 171-185.

22. Georges JL, Regis-Bailly A, Salah D, 1996 Family study of lipoprotein lipase gene polymorphisms and plasma triglyceride levels. Genet Epidemiol 13: 179-192.

23. Razzaghi H, Aston CE, Hamman RF, 2000 Genetic screening of the lipoprotein lipase gene for mutations associated with high triglyceride/low HDL-cholesterol levels. Hum Genet 107: 257-267.

24. Malygina NA, Melent'ev AS, Kostomarova IV, 2001 Connection of HindIII-polymorphism in the lipoprotein lipase gene with myocardial infarct and life span in elderly ischemic heart disease patients. Mol Biol
(Mosk) 35: 787-791.

25. Mahley RW, 1988 Apolipoprotein E, cholesterol transport protein with expanding role in cell biology. Science 240: 622-630.

26. Mahley RW, Rall SC Jr, 2000 Apolipoprotein E, far more than a lipid transport protein. Annu Rev Genomics Hum Genet 1: 507-537.

27. Kolovou G, Damaskos D, Anagnostopoulou K, Cokkinos DV, 2009 Apolipoprotein E gene polymorphism and gender. Ann Clin Lab Sci 39: 120-133.

28. Kolovou GD, Anagnostopoulou KK, Kostakou P, et al, 2009 Apolipoprotein E gene polymorphism and obesity status in middle-aged men with coronary heart disease. In Vivo 23: 33-39.

29. Kolovou GD, Anagnostopoulou KK, Cokkinos DV, 2009 Apolipoprotein E gene polymorphism and myocardial infarction. Int J Cardiol 133: 264-265.

30. Muros M, Rodríguez-Ferrer C, 1996 Apolipoprotein E polymorphism influence on lipids, apolipoproteins and $\mathrm{Lp}(\mathrm{a})$ in a Spanish population underexpressing apo E4. Atherosclerosis 121: 13-21.

31. Gómez-Coronado D, Alvarez JJ, Entrala A, Olmos JM, Herrera E, Lasunción MA, 1999 Apolipoprotein E polymorphism in men and women from a Spanish population: allele frequencies and influence on plasma lipids and apolipoproteins. Atherosclerosis 147: 167-176.

32. Humphries SE, Nicaud V, Margalef J, Tiret L, Talmud PJ, 1998 Lipoprotein lipase gene variation is associated with a paternal history of premature coronary artery disease and fasting and postprandial plasma triglycerides: the European Atherosclerosis Research Study (EARS). Arterioscler Thromb Vasc Biol 18: 526-534.

33. Hixson JE, Vernier DT, 1990 Restriction isotyping of human apolipoprotein $\mathrm{E}$ by gene amplification and cleavage with HhaI. J Lipid Res 31: 545-548.

34. Kolovou G, Yiannakouris N, Hatzivassiliou M, et al, 2002 Association of apolipoprotein E polymorphism with myocardial infarction in Greek patients with coronary artery disease. Curr Med Res Opin 18: 118-124.

35. Xin X, Srinivasan SR, Chen W, Boerwinkle E, Berenson GS, 2003 Interaction effect of Serine447Stop variant of the lipoprotein lipase gene and C-514T variant of the hepatic lipase gene on serum triglyceride levels in young adults: the Bogalusa Heart Study. Metabolism 52: 1337-1342.

36. Barg E, 2011 Polymorphisms of lipoprotein lipase gene and their participation in metabolic processes. Pediatr Endocrinol Diabetes Metab 17: 107-112.

37. Agirbasli M, Sumerkan MC, Eren F, Agirbasli D, 2011 The S447X variant of lipoprotein lipase gene is inversely associated with severity of coronary artery disease. Heart Vessels 26: 457-463.

38. Baik I, Lee S, Kim SH, Shin C, 2013 Lipoprotein Lipase Gene Polymorphism Interacts with Consumption of Alcohol and Unsaturated Fat to Modulate Serum HDLCholesterol Concentrations. J Nutr 143: 1618-1625. 
39. Aydogan HY, Isbir S, Kurnaz O, Gormus U, Isbir T, 2009 Associations of lipoprotein lipase S447X and apolipoprotein E genotypes with low-density lipoprotein subfractions in Turkish patients with coronary artery disease. In Vivo 23: 155-161.

40. Abd-El-Aziz TA, Mohamed RH, El-Shal AS, 2013 Synergistic effect between lipoprotein lipase and apolipoprotein $\mathrm{C} 3$ genes in determining the severity of coronary artery disease. J Cardiovasc Transl Res 6: 430-435.

41. Al-Jafari AA, Daoud MS, Mobeirek AF, Al Anazi MS, 2012 DNA polymorphisms of the lipoprotein lipase gene and their association with coronary artery disease in the Saudi population. Int J Mol Sci 13: 7559-7574.

42. Munshi A, Babu MS, Kaul S, Rajeshwar K, Balakrishna N, Jyothy A, 2012 Association of LPL gene variant and LDL, HDL, VLDL cholesterol and triglyceride levels with ischemic stroke and its subtypes. J Neurol Sci 318: 51-54.

43. Muñoz-Barrios S, Guzmán-Guzmán IP, Muñoz-Valle JF, Salgado-Bernabé AB, Salgado-Goytia L, ParraRojas I, 2012 Association of the HindIII and S447X polymorphisms in LPL gene with hypertension and type 2 diabetes in Mexican families. Dis Markers 33: 313-320.

44. Rebhi L, Kchok K, Omezzine A, et al, 2012 Six lipoprotein lipase gene polymorphisms, lipid profile and coronary stenosis in a Tunisian population. Mol Biol Rep 39: 9893-9901.

45. Wang XL, McCredie RM, Wilcken DEL, 1996 Common DNA Polymorphisms at the Lipoprotein Lipase Gene:
Association with Severity of Coronary Artery Disease and Diabetes Circulation 93: 1339-1345.

46. Ma YQ, Thomas GN, Ng MC, Critchley JA, Chan JC, Tomlinson B, 2003 The lipoprotein lipase gene HindIII polymorphism is associated with lipid levels in earlyonset type 2 diabetic patients. Metabolism 52: 338-343.

47. Mitchell RJ, Earl L, Bray P, Fripp YJ, Williams J, 1994 DNA polymorphisms at the lipoprotein lipase gene and their association with quantitative variation in plasma high-density lipoproteins and triacylglycerides. Hum Biol 66: 383-397.

48. Peacock RE, Hamsten A, Nilsson-Ehle P, Humphries SE, 1992 Associations between lipoprotein lipase gene polymorphisms and plasma correlations of lipids, lipoproteins and lipase activities in young myocardial infarction survivors and age-matched healthy individuals from Sweden. Atherosclerosis 97: 171-185.

49. Heinzmann C, Kirchgessner T, Kwiterovich PO, et al, 1991 DNA polymorphism haplotypes of the human lipoprotein lipase gene: possible associations with highdensity lipoprotein levels. Hum Genet 86: 578-584.

50. Vohl MC, Lamarche B, Moorjani S, et al, 1995 The lipoprotein lipase HindIII polymorphism modulates plasma triglyceride levels in visceral obesity. Arterioscler Thromb Vasc Biol 15: 714-720.

51. Jemaa R, Tuzet S, Portos C, Betoulle D, Apfelbaum M, Fumeron F, 1995 Lipoprotein lipase gene polymorphisms: associations with hypertriglyceridemia and body mass index in obese people. Int J Obes Relat Metab Disord 19: 270-274. 